\title{
The effects of instructions on recall and recognition of categorized lists by the elderly
}

\author{
THOMAS D. OVERCAST \\ Western Washington State College, Bellingham, Washington 98225 \\ MARTIN D. MURPHY \\ University of Illinois, Champaign, Illinois 61820 \\ SANDRA S. SMILEY \\ Western Washington State College, Bellingham, Washington 98225 \\ and \\ ANN L. BROWN \\ University of Illinois, Champaign, Illinois 61820
}

\begin{abstract}
Sixty noninstitutionalized elderly people were tested for recall of both taxonomic and thematically related lists. On Trial 1, subjects were instructed either to look at, categorize, or remember the pictures; on Trial 2, they were all required only to look at the items. Subjects instructed to remember or categorize recalled and clustered more than subjects required only to look. Although there were no differences due to category type on the first trial, when freed from the restriction to organize or memorize on Trial 2, subjects performed better on the thematic lists. The results are discussed in terms of the possible effects of institutionalization and age-related shifts in the logical basis for classification.
\end{abstract}

Reviews of research with gerontological populations have indicated that the elderly are less likely than young adults to use: mediational devices in paired-associate learning (Hulicka \& Grossman, 1967); spontaneous rehearsal (Kausler, 1970); and input organization in free-recall situations (Hultsch, 1971). The suggestion is that elderly people suffer from a production deficiency in the use of mnemonics similar to that found with young children (Brown, 1974). Evidence to support this hypothesis is, however, scanty and appears to be related to factors other than age alone, such as verbal facility (Craik, 1968) and institutionalization (Denney \& Denney, 1973). Before considering production deficiencies in the spontaneous use of specific mnemonics, it might prove instructive to consider whether a more primitive general deficiency in producing any strategy underlies a performance decrement in the elderly, as it does with very young children. Deliberate memorization strategies following instructions to remember are apparent only in older children (Appel, Cooper, McCarrell, Sims-Knight, Yussen, \& Flavell, 1972). Of interest is whether elderly persons introduce more active strategies when instructed to remember than they do when instructed to look at pictures.

This research was supported by USPHS Grants HD06864 and HD05951. The authors wish to thank Mrs. May and Mrs. Hurbut and all the participants from the Bellingham Senior Activity Center, Bellingham, Washington, for their willing and generous cooperation. Requests for reprints should be sent to Ann $L$. Brown, Children's Research Center, 51 Gerty Drive, Champaign, Illinois 61820 .
Furthermore, if active strategies are produced, the type of strategy adopted would be of interest. Given categorized lists, the optimal strategy would appear to be some form of classification (Mandler, 1967). Therefore, an additional group of subjects was included who received explicit instructions to categorize, so that performance under remember instructions, where the optimal strategy must be produced spontaneously, could be compared with conditions where the strategy was explicitly instructed.

The second focus of this study was to consider the particular logical classifications used by the elderly. Young children prefer to categorize on the basis of thematic relationship, i.e., to group items that share some interrelationship either in the subject's past experience or in the experimental situation (e.g., baby-crib, hammer-nail, horse-saddle). College students, however, prefer groups based on taxonomic categories (e.g., vehicles, animals, etc.). There is some evidence that the elderly may revert to thematic groupings because such groupings are a "more natural way of organizing one's experience" (Denney, 1974). Thus, in the present study, the use of spontaneous and instructed categorization was compared for both thematic and taxonomic categories.

\section{METHOD}

\author{
Subjects \\ Sixty senior citizens attending a Senior Activity Center were \\ listed. None of the subjects were residents of institutes for the
}


elderly. They ranged in age from 62-85 years with a mean of 74.24 years. The median level of schooling completed was eighth grade.

\section{Stimuli}

Four lists of 16 colored pictures were used each consisting of four items in each of four categories. Two lists contained taxonomic categories and two lists contained thematic categories.

\section{Procedure}

All subjects were randomly assigned to lists and to one of six groups, resulting from the factorial combination of 3 instructions by 2 list orders. The list types were either thematic or taxonomic. All subjects received both list types. For half the subjects, the order of lists was taxonomic on Trial 1, followed by thematic on Trial 2. For the remaining subjects, the order was the reverse. The three instructions were the look, categorize, and remember conditions.

On each trial, the pictures were placed in a random order face down on a table. The subjects were required to expose and label the items in all conditions. In addition, subjects were required to "look at," "categorize," or "try to remember" the items depending on the condition to which they were assigned. Following the viewing, the subjects were given a surprise recall test, which in turn was followed by the presentation of the second list under modified look instructions. All subjects were thanked for their participation and were told that it would be helpful if they would look at and label the new items and indicate if any were unclear for they were to be used with the next subject. This was again followed by a surprise memory test. $^{1}$

\section{RESULTS AND DISCUSSION}

Preliminary inspection of the recall data revealed no difference due to specific lists or to age, sex, and years of formal schooling of the subjects. Separate analyses were carried out on recall and clustering measures (Frankel \& Cole, 1971). The variables included in the analyses were instructions, list order, and trials, with repeated measures on the last variable. The primary data are shown in Table 1. On the recall analysis, there were reliable effects obtained due to list order $[F(1,54)=$ $5.78, \mathrm{p}<.025]$; trials, $[\mathrm{F}(1,54)=123.50, \mathrm{p}<.001]$, and the Instructions by Trials interaction $[F(2,54)=$ 9.53, $\mathrm{p}<.001]$. Given the interaction, separate Instructions by List Order Analyses were conducted for each trial. The analysis of Trial 1 yielded only an effect due to instructions $[F(2,54)=4.47, p<.025]$. Those subjects required to categorize performed on a par with those instructed to remember, and both groups recalled more items than those subjects instructed only to look at the pictures. On Trial 2, the instructions variable was, as expected, not reliable, since all subjects were given the same instructions. The only reliable effect obtained on the Trial 2 analysis was due to list order $[F(1,54)=6.79$, $\mathrm{p}<.025]$. Subjects given a thematic list on Trial 2 recalled more items (7.90) than those given a taxonomic list (6.07).

Regarding the overall clustering analysis, reliable effects were obtained due to instructions $[F(2,53)=$ $3.80, \mathrm{p}<.03]$, trials $[\mathrm{F}(1,53)=37.25, \mathrm{p}<.001]$, and the Instructions by Trials interaction, $[\mathrm{F}(2,53)=6.04$,
Table 1

The Mean Recall and Clustering Scores as a Function of Instructions and Trials

\begin{tabular}{|c|c|c|c|c|c|}
\hline \multicolumn{2}{|c|}{ Instructions } & \multicolumn{2}{|c|}{ Recall } & \multicolumn{2}{|c|}{ Clustering $\mathrm{Z}^{*}$} \\
\hline Trial 1 & Trial 2 & Trial 1 & Trial 2 & Trial 1 & Trial 2 \\
\hline Look & Look & 9.45 & 7.65 & 2.00 & 1.73 \\
\hline Cat. & Look & 11.95 & 6.80 & 3.61 & 1.74 \\
\hline Rem. & Look & 11.70 & 6.50 & 2.79 & .82 \\
\hline
\end{tabular}

*With 20 subjects, any mean $Z$ score greater than .44 repre. sents above chance clustering.

$p<.005]$. As with the recall measure, separate instructions by list order analyses were conducted for each trial. On the Trial 1 analysis, the only significant source of variance was instructions $[\mathrm{F}(2,53)=4.85$, $\mathrm{p}<.02]$. As can be seen in Table 1 , the subjects instructed to categorize showed the highest clustering scores, and those instructed simply to look at the pictures showed the least clustering. Instructing subjects to remember increased clustering relative to look instructions, but not to the degree shown by those instructed to categorize the pictures.

In Trial 2, the instructions effect was again reliable $[F(2,53)=4.24, p<.02]$. The subjects given remember instructions on Trial 1 showed less clustering on Trial 2 than the remaining subjects. It is not clear why this result was obtained. However, it is possible that the look instructions were more effective here in inhibiting the subjects' organization, as these were the only subjects who had not previously received a surprise memory test. In addition to the instructions effect, the list order variable approached significance $[F(1,53)=3.03$, $.10>p>.05]$. Subjects given a thematic list on Trial 2 showed more clustering $(\overline{\mathrm{X}}=1.69)$ than those given a taxonomic list $(\overline{\mathrm{X}}=1.17)$. This result fits nicely with the recall data as the subjects who received a thematic list on Trial 2 recalled more items on that trial than those given a taxonomic list.

The elderly adopt deliberate memorization strategies following instructions to remember. As a result, they recall more items than when merely required to view and name the stimuli. This effect was found when both between- and within-subjects comparisons were made. All subjects were able to categorize when instructed to do so. There were no differences in recall following remember or categorize conditions, even though it was only in the remember condition that subjects were specifically warned that they would be required to remember. Similar results have been found with young adults (Mandler, 1967). Apparently, for young and elderly adults, involuntary memory following categorization is as efficient as voluntary strategies for memorization. The effect of the remember instructions is to induce the appropriate activity, in this case, categorization.

There were no differences between subjects assigned to either a thematic or a taxonomic list on the first trial, 
either in ability to sort, according to the experimenter, defined categories or in the amount of recall and clustering. Apparently, elderly individuals are capable of grouping according to both criteria when specifically instructed to memorize or categorize. However, on Trial 2, when freed from the necessity of remembering or organizing, superior recall and clustering were found on the thematic lists compared with the taxonomic list. Thus, young children (Denney \& Ziobrowski, 1972), unschooled African children (Cole, Gay, Glick, \& Sharp, 1971), and the elderly (Denney \& Lennon, 1972), categorize more readily according to thematic criteria, because this is a more natural way of organizing experience for individuals who are relatively free from educational or occupational pressures to use higher order concepts (Denney, 1974). While they can sort and do cluster according to both criteria if required (Trial 1), when freed from the restriction that they must organize or remember the material, they recall and cluster more on the thematic lists.

As a final point, it should be noted that the elderly subjects who participated in this experiment were all living normal active lives, outside of institutions. It has been suggested that a decline in the ability to form logical classifications may be related to institutionalization (Denney \& Denney, 1973) rather than any neurologically related decline in, for example, fluid intelligence (Horn, 1970). Thus, both the efficient use of strategies and the facility with which the present subjects used both complementary and taxonomic categories could be due to the fact that a noninstitutionalized population was the subject of study. Further research is needed on the effects, if any, of institutionalization on cognitive ability in the elderly.

\section{REFERENCES}

Appel, L. F., Cooper, R. G., McCarrell, N., Sims-Knight, J., Yussen, S. R., \& Flavell, J. H. The development of the distinction between perceiving and memorizing. Child Development, 1972, 43, 1365-1381.

Brown, A. L. The role of strategic behavior in retardate memory. In N. R. Ellis (Ed.), International review of research in mental retardation. Vol. 7, Academic Press, 1974, Pp. 55-111.

Cole, M., Gay, J., Glick, J., \& Sharp, D. W. The cultural context of learning and thinking. New York: Basic Books, 1971.

Craik, F. I. M. Short-term memory and the aging process. In G. A. Talland (Ed.), Human aging and behavior. New York: Academic Press, 1968, Pp. 131-168.

Denney, D. R., \& Denney, N. W., The use of classification for problem solving: A comparison of middle and old age. Developmental Psychology, 1973, 9, 275-278.

Denney, N. W. Evidence for developmental changes in categorization criteria. Human Development, 1974, 17, 41-53.

Denney, N. W., \& Ziobrowski, M. Developmental changes in clustering criteria. Journal of Experimental Child Psychology, 1972, 13, 275-283.

Frankel, F., \& Cole, M. Measures of category clustering in free recall. Psychological Bulletin, 1971, 76, 39-45.

Horn, J. L. Organization of data on life-span development of human abilities. In L. R. Goulet \& P. B. Baltes (Eds.), Life-span developmental psychology: Theory \& research. New York: Academic Press, 1970. Pp. 424-464.

Hulicka, J. M., \& Grossman, J. L. Age-group comparisons for the use of mediators in paired-associated learning. Journal of Gerontology, 1967, 22, 46-51.

Hultsch, D. F. Organization and memory in adulthood. Human Development, 1971, 14, 16-29.

Kausler, D. H. Retention-forgetting as a nomological network for developmental research. In $L$. R. Goulet and P. B. Baltes (Eds.), Life-span developmental psychology: Theory \& research. New York: Academic Press, 1970, Pp. 306-353.

Mandler, G. Organization and memory. In K. W. Spence and J. T. Spence (Eds.), Psychology of learning and motivation, Vol. 1. New York: Academic Press, 1967.

\section{NOTE}

1. Following recall attempts, subjects were required to select the 16 list items from a set of 32 , containing 16 distractors from the same conceptual category. Performance was virtually errorless on the recognition trials.

(Received for publication January 3, 1975.) 